Journal Club

Editor's Note: These short, critical reviews of recent papers in the Journal, written exclusively by graduate students or postdoctoral fellows, are intended to summarize the important findings of the paper and provide additional insight and commentary. For more information on the format and purpose of the Journal Club, please see http://www.jneurosci.org/misc/ifa_features.shtml.

\title{
Network Mechanisms Underlying the Initiation and Generation of Sharp-Wave-Associated Ripple Oscillations
}

\author{
Jagdish Patel \\ NYU Neuroscience Institute, Langone Medical Center, New York University, New York, New York 10016 \\ Review of Schlingloff et al.
}

Network oscillations of different amplitudes, frequencies, and durations occur during different states and behaviors and are hypothesized to coordinate information processing across brain areas. Hippocampal sharp-wave-associated ripple (SWR) oscillations $(\sim 140-200 \mathrm{~Hz})$ are the largest recorded brain signals of physiological significance (Buzsáki et al., 1992). Spontaneous SWRs occur as 50-100 ms epochs during slow-wave sleep (SWS), awake immobility, and consummatory behaviors like eating, drinking, and rearing. During each SWR, $\sim 10-20 \%$ ( 50,000-100,000) of all pyramidal neurons in the rat hippocampal complex produce action potentials (Csicsvari et al., 2000). Moreover, spontaneous SWRs have been recorded from all regions of the hippocampal complex including CA1, CA3, subiculum, presubiculum, parasubiculum and the deep layers of the entorhinal cortex (Chrobak and Buzsáki, 1996), across rodents (Buzsáki et al., 1992), nonhuman primates (Skaggs et al., 2007), and humans (Bragin et al., 1999). It is hypothesized that such synchronous population patterns are essential for the faithful transfer of information from the hippocampus to downstream cortical structures (Buzsáki et al.,

Received Oct. 12, 2014; revised Nov. 24, 2014; accepted Dec. 3, 2014.

We thank Brendon Watson and Gyorgy Buzsaki for helpful comments on the manuscript.

Correspondence should be addressed to Jagdish Patel, NYU Neuroscience Institute, Langone Medical Center, New York University, East River Science Park, Alexandria Center, 450 East 29th St, Ninth Floor, New York, NY 10016. E-mail: jagdish.patel@nyumc.org or jprutgers@gmail.com.

DOI:10.1523/JNEUROSCI.4215-14.2015

Copyright $\odot 2015$ the authors $\quad 0270-6474 / 15 / 352323-03 \$ 15.00 / 0$
1983). Furthermore, several experiments have shown that these intermittent highfrequency oscillatory events of the hippocampus subserve the role of memory consolidation (Girardeau et al., 2009; Jadhav et al., 2012; see also O'Neill et al., 2010).

Despite clear evidence for the physiological role of SWR oscillations and past work on the mechanistic aspects of SWRs in the hippocampus, the underlying cellular and network mechanisms for the generation and initiation of SWR oscillations are still debated. Two recent papers use electrophysiology and pharmacology along with selective manipulation of neuronal subtypes using optogenetics to advance our understanding of the cellular network mechanisms underlying the generation and initiation of hippocampal SWR oscillations (Stark et al., 2014; Schlingloff et al., 2014). The studies were performed under varying conditions: one examined the CA1 region of the hippocampus in vivo (Stark et al., 2014) and the other investigated the CA3 region in vitro (Schlingloff et al., 2014). But the objective of both studies was to clarify and limit existing models of the cellular network mechanisms underlying the initiation and generation of SWR oscillations in the hippocampus.

Despite inherent differences in CA1 and CA3 circuitry in terms of feedforward versus recurrent circuitry and unidirectional projections from CA3 to CA1, critical results were shared by the two studies: (1) removing perisomatic inhibition of pyramidal cells with gabazine (in vitro) or picrotoxin (in vivo) aborted spontaneous
SWRs and decreased sharp-wave amplitude, despite increasing pyramidal cell firing rates; (2) activation of paralbumin basket cells (PVBCs) paced ripple-frequency firing suggesting that the reciprocal connections between PVBCs play an essential role in ripple generation and synchrony. Support for PVBCs as the pacemaker of ripple frequency also comes from the finding that PVBC dendrites generate propagating $\mathrm{Ca}^{2+}$ spikes during SWRs (Chiovini et al., 2014); (3) optogenetic activation of local population of pyramidal cells in the CA1 region was sufficient to artificially induce high-frequency oscillations (HFOs) in vivo, similar to spontaneous ripples in the behaving animal. In comparison, higher-amplitude baseline excitatory activity (EPSPs) reflecting the activation of local pyramidal cells, was a necessary precondition for ripple generation in the slices; and (4) silencing pyramidal cells either directly or indirectly via interneuron-mediated inhibition aborted spontaneous ripples in both the cases. The necessity of similar network conditions for SWRs in both CA1 and CA3 regions indicate that the underlying mechanism for the generation and initiation of ripples in these regions could be same despite the spectral-temporal differences in the ripples generated in these regions (Csicsvari et al., 2000; Sullivan et al., 2011).

While four critical results were shared by the in vivo study in CA1 and in vitro study in CA3, one result was not shared. Surprisingly, while activation of PVBCs quickly disrupted ongoing ripples in CA1 
in vivo, tonic excitation of mutually connected PVBCs was necessary and sufficient to generate HFOs in CA3 in slices even when excitation was blocked.

In addition to providing insights about network mechanisms that generate SWR across CA1 and CA3 networks, these two studies provide concrete answers to important related questions. (1) Can ripples be artificially generated in hippocampal circuits? Yes. Stark and colleagues (2014) repeatedly and reliably generated HFOs in both behaving and anesthetized mice and rats. The amplitude, frequency, and duration profiles of these artificially induced HFOs (iHFOs) were similar to those of spontaneous SWRs. Furthermore, both the frequency and the amplitude of iHFOs were correlated with the stimulation intensity, just as the frequency and amplitude of spontaneous ripples are correlated with sharp wave amplitude. (2) What is the minimal network size needed to generate a ripple? A network of $\sim 80$ pyramidal cells was estimated to be sufficient to generate a reliably detectable ripple. This has strong implications and suggests that each ripple can be unique even by its size. (3) Is there any precise and reliable dynamic between participating ensembles of pyramidal cells and interneurons during a SWR? Previous modeling work with realistic synaptic parameters suggested that in networks without recurrent connections, like CA1, HFOs can occur when pyramidal neurons precede interneuron firing by $\sim 90^{\circ}$ during ripple troughs (Brunel and Wang, 2003). Indeed, Stark and colleagues (2014) find that pyramidal cells precede interneuron firing by $90^{\circ}$ during each ripple cycle. (4) What mechanisms support the organization of SWRs along the long septo-temporal axis given that ripples have been reported to occur across large CA1 longitudinal distances (Buzsáki et al., 1992; Ylinen et al., 1995; Csicsvari et al., 2000; Patel et al., 2013)? To understand how widespread ripples are generated, Stark and colleagues (2014) simultaneously illuminated pyramidal cells at multiple sites (electrode probe shanks). They found that such massive stimulation can generate phase-locked oscillations across illuminated shanks. While iHFOs during simultaneous multisite stimulation had higher power and less inter-site frequency variability, their overall common frequency had dropped; this was tested for distances up to $\sim 1.4 \mathrm{~mm}$. The reduction in global frequency once again follows the modeling prediction that the larger the network size that generates HFOs, the lower the overall global frequency of the HFO (Brunel and Wang, 2003).

It has also been reported that the average ripple frequency decreases from the septal to temporal pole of the hippocampus (Patel et al., 2013). While $\sim 40 \%$ of ripples tend to be synchronized across up to $6 \mathrm{~mm}$ (Patel et al., 2013), another 40\% propagate along the septo-temporal (ST) or temporo-septal (TS) direction (Patel et al., 2013). This raises the question of what permits the widespread spatial synchronization of these physiologically important short-lasting bursts of firing within the CA1 layer? Given only sparse excitatory recurrent connectivity and equally sparse long inhibitory projections within the CA1 region, we still do not know how spatially widespread synchronous SWRs come about in CA1. Whatever mechanisms are responsible for the widespread synchronous or ST or TS propagating SWRs, these mechanisms must uniquely participate during SWRs because unlike ripples, which primarily occur during SWS, theta oscillations, which occur during awake states, travel unidirectionally (Patel et al., 2012).

SWRs are highly irregular in their occurrence and their rate has been reported to vary from 0.01 to $2 \mathrm{~Hz}$. Schlingloff and colleagues (2014) went beyond what had been explored in terms of mechanistic aspects of SWR generation in the past (Ellender et al., 2010) and asked whether there was any limit to the highest frequency with which SWRs can occur. They found that while a minimum network size was required to observe spontaneous SWRs in slices, the occurrence rate increased with slice thickness. However, they note that even in thick slices there was an absolute refractory period of $\sim 200$ $\mathrm{ms}$ at the cellular or network level after a SWR occurred.

The finding that a minimum level of excitation among excitatory neurons is necessary for CA1 or CA3 network to generate a SWR is consistent across both studies. However, the conclusion about absolute refractory period is weakened by the fact that although total neuronal participation reaches up to $\sim 20 \%$ during a SWR, pyramidal cells fire at most once during each ripple. So what causes the universal inter-ripple interval of $\sim 200$ $\mathrm{ms}$, given that a large fraction of both pyramidal cells and interneurons are not participating in each event? While attempting to answer this question, we have to keep in mind that historically in vivo SWR occurrence have been reported to be highly irregular, while there are several re- ports of regularity of ripple occurrence in slice work (Ellender et al., 2010). The reason for this variance between in vivo and in vitro work could be the availability of neuromodulators in the whole animal. Even though most neuromodulators are downregulated during sleep, a select few, like adenosine and nitric oxide, promote sleep (Brevig and Baghdoyan, 2010; Wisor et al., 2011). These neuromodulators could be responsible for the irregular occurrence of SWRs in whole animals, whereas their absence could be responsible for the more regular occurrence of SWRs in slices. But how would neuromodulators introduce irregularity? One answer could come from the knowledge that hippocampal ripples can be triggered by both cortical spindles and down-up state transitions and the interference of the timing of these rhythms might result in irregular intervals between consecutive ripples (Sullivan et al., 2011). Separately, the amplitude irregularity of SWRs might arise from the lognormal (skewed) distribution of the magnitude of population synchrony during ripples (Buzsáki and Mizuseki, 2014) and the increasing number of participating pyramidal cells and interneurons with each cycle.

Together, the two studies discussed here limit the possible mechanisms responsible for the generation of SWRs and tell us that the process for ripple generation begins from a build-up of excitation in the excitatory networks of CA1/CA3, in turn driving PVBCs. Subsequently, the strong recurrent connectivity between PVBCs with small fixed time constants lead to organized inhibition at $200 \mathrm{~Hz}$, creating opportunity for select large ensembles of pyramidal cells in CA1/CA 3 to fire synchronously during intermittent decreased inhibition at $\sim 3-4 \mathrm{~ms}$ after phase-locked firing of PVBCs, giving rise to LFP ripple waves. However, knowing critical steps necessary for the generation of SWRs only raises more questions. How are cells recruited to fire during certain ripples and not others? What is the empirical size of large ensembles that fire during spatially synchronous SWR that occur over $5 \mathrm{~mm}$ of septo-temporal space? While spatially widespread SWRs may hold intuitive value in consolidation of memory over the large hippocampal space, what exactly is the functional role of propagating ripples? Do cells recruited during synchronous SWRs differ from cells recruited during propagating SWRs? The quest to find answers to such important questions will take us a step further in the direction of understanding how the 
hippocampus contributes to learning and memory.

\section{References}

Bragin A, Engel J Jr, Wilson CL, Fried I, Buzsáki G (1999) High-frequency oscillations in human brain. Hippocampus 9:137-142. CrossRef Medline

Brevig HN, Baghdoyan HA (2010) Neurotransmitters and neuromodulators regulating sleep and wakefulness. In: Encyclopedia of behavioral neuroscience, vol. 3 (Koob GF, Le Moal M, Thompson RF, eds.), pp 456-463. Oxford: Academic

Brunel N, Wang XJ (2003) What determines the frequency of fast network oscillations with irregular neural discharges? I. Synaptic dynamics and excitation-inhibition balance. J Neurophysiol 90:415-430. CrossRef Medline

Buzsáki G, Mizuseki K (2014) The log-dynamic brain: how skewed distributions affect network operations. Nat Rev Neurosci 15:264278. CrossRef Medline

Buzsáki G, Leung LW, Vanderwolf CH (1983) Cellular bases of hippocampal EEG in the behaving rat. Brain Res 287:139-171. Medline

Buzsáki G, Horváth Z, Urioste R, Hetke J, Wise K (1992) High-frequency network oscillation in the hippocampus. Science 256:1025-1027. CrossRef Medline

Chiovini B, Turi GF, Katona G, Kaszás A, Pálfi D, Maák P, Szalay G, Szabó MF, Szabó G, Szadai Z, Káli S, Rózsa B (2014) Dendritic spikes induce ripples in parvalbumin interneurons during hippocampal sharp waves. Neuron 82: 908-924. CrossRef Medline

Chrobak JJ, Buzsáki G (1996) High-frequency oscillations in the output networks of the hippocampal-entorhinal axis of the freely behaving rat. J Neurosci 16:3056-3066. Medline

Csicsvari J, Hirase H, Mamiya A, Buzsáki G (2000) Ensemble patterns of hippocampal CA3-CA1 neurons during sharp wave-associated population events. Neuron 28:585-594. CrossRef Medline

Ellender TJ, Nissen W, Colgin LL, Mann EO, Paulsen O (2010) Priming of hippocampal population bursts by individual perisomatictargeting interneurons. J Neurosci 30:59795991. CrossRef Medline

Girardeau G, Benchenane K, Wiener SI, Buzsáki G, Zugaro MB (2009) Selective suppression of hippocampal ripples impairs spatial memory. Nat Neurosci 12:1222-1223. CrossRef Medline

Jadhav SP, Kemere C, German PW, Frank LM (2012) Awake hippocampal sharp-wave ripples support spatial memory. Science 336: 1454-1458. CrossRef Medline

O’Neill J, Pleydell-Bouverie B, Dupret D, Csicsvari J (2010) Play it again: reactivation of waking experience and memory. Trends Neurosci 33:220-229. CrossRef Medline

Patel J, Fujisawa S, Berényi A, Royer S, Buzsáki G (2012) Traveling theta waves along the entire septotemporal axis of the hippocampus. Neuron 75:410-417. CrossRef Medline

Patel J, Schomburg EW, Berényi A, Fujisawa S,
Buzsáki G (2013) Local generation and propagation of ripples along the septotemporal axis of the hippocampus. J Neurosci 33: 17029-17041. CrossRef Medline

Schlingloff D, Káli S, Freund TF, Hájos N, Gulyás AI (2014) Mechanisms of sharp wave initiation and ripple generation. J Neurosci 34: 11385-113898. CrossRef Medline

Skaggs WE, McNaughton BL, Permenter M, Archibeque M, Vogt J, Amaral DG, Barnes CA (2007) EEG sharp waves and sparse ensemble unit activity in the macaque hippocampus. J Neurophysiol 98:898-910. CrossRef Medline

Stark E, Roux L, Eichler R, Senzai Y, Royer S, Buzsáki G (2014) Pyramidal cell-interneuron interactions underlie hippocampal ripple oscillations. Neuron 83:467-480. CrossRef Medline

Sullivan D, Csicsvari J, Mizuseki K, Montgomery S, Diba K, Buzsáki G (2011) Relationships between hippocampal sharp waves, ripples, and fast gamma oscillation: influence of dentate and entorhinal cortical activity. J Neurosci 31:86058616. CrossRef Medline

Wisor JP, Gerashchenko D, Kilduff TS (2011) Sleepactive neuronal nitric oxide synthase-positive cells of the cerebral cortex: a local regulator of sleep? Curr Top Med Chem 11:2483-2489. CrossRef Medline

Ylinen A, Bragin A, Nádasdy Z, Jandó G, Szabó I, Sik A, Buzsáki G (1995) Sharp wave-associated high-frequency oscillation $(200 \mathrm{~Hz})$ in the intact hippocampus: network and intracellular mechanisms. J Neurosci 15:30-46. Medline 